\title{
RESUSCITATION
}

\section{Potential impact of emergency intervention on sudden deaths from coronary heart disease in Glasgow}

\author{
Bridie Fitzpatrick, Graham C M Watt, Hugh Tunstall-Pedoe
}

\begin{abstract}
Objective-To determine the potential impact of emergency intervention strategies to prevent deaths from coronary heart disease outside hospital.

Design-Analysis of routine medical and legal records of all persons dying of coronary heart disease in a defined population.

Setting-Glasgow City, north of the river Clyde, 1984.

Subjects -420 people under 65 years for whom the underlying cause of death on the death certificate was coronary heart disease (ICD 410-414, 9th Revision).
\end{abstract}

Results-Of the 296 deaths outside hospital, $73 \%$ occurred at home. The deaths of $\mathbf{4 0} \%$ of those who died outside hospital were not witnessed and these people could not have received prompt cardiopulmonary resuscitation. Only $16 \%$ of the witnesses of a death attempted cardiopulmonary resuscitation before the arrival of a doctor or an ambulance crew. Over half $(53 \%)$ of the cases in which cardiopulmonary resuscitation could have been attempted by a witness, but was not attempted, death occurred in the presence of the spouse or other close relative. Death occurred in the presence of a duty doctor or the ambulance crew in a maximum of $5 \%$ of deaths outside hospital. Ninety one per cent of people were dead before a call for help was made.

Conclusion-Unless a greater proportion of patients receive cardiopulmonary resuscitation before emergency staff arrive at the scene the provision of emergency care staff with defibrillators is unlikely to have a significant impact on deaths outside hospital caused by coronary heart disease.

Most coronary deaths occur outside hospital. ${ }^{12}$ Strategies to reduce the number of deaths include the provision of ambulance crews with defibrillators and education of the public in techniques of cardiopulmonary resuscitation. The likely impact of these strategies on coronary mortality outside hospital has not been assessed. In March 1989, the House of Commons Public Accounts Committee reported that there were no reliable data on the place and timing of coronary deaths in the community or the number of deaths that occur in the presence of ambulance crews or shortly before their arrival. ${ }^{3}$ This study uses data from the Glasgow MONICA Project to assess the potential impact of these strategies to reduce coronary mortality outside hospital. The data are those for 1984, before any such developments had been introduced in Glasgow.

\section{Patients and methods}

The study was set in Glasgow, north of the river Clyde (table 1) in an area that is almost half of the city. It was based on 420 deaths in residents under 65 years of age occurring in 1984 for which the underlying cause of death on the death certificate was coronary heart disease (codes 410-414, International Classification of Diseases, 9th Revision). Data for 1984 from 32 other centres participating in the World Health Organisation (WHO) MONICA Project showed that Glasgow north of the Clyde had the fourth highest coronary mortality for men and the highest rate for women. ${ }^{4}$

We investigated each case in order to determine:

(a) The available clinical data in support of the diagnosis made at death, including symptoms, electrocardiograph and cardiac enzyme results, previous medical history, and necropsy findings. ${ }^{5}$

(b) The time and place of death, defined as the time and the place where irreversible cardiac arrest occurred.

(c) Whether the death was witnessed and by whom.

(d) Whether cardiopulmonary resuscitation was attempted and by whom.

Table 1 Study population: Glasgow, north of the River Clyde, 25-64 years old (1981 Census)

\begin{tabular}{llc}
\hline & Glasgow City & Glasgow, north of the Clyde \\
\hline Men & 153246 & 95600 \\
Women & 181437 & 102600 \\
Total & 334683 & 198200 \\
\hline
\end{tabular}


(e) The medical and legal personnel who were involved after death had occurred.

(f) Whether there had been contact with a medical practitioner in the 28 days preceding death.

There were three main sources of information. The records of the Glasgow Death Unit were reviewed for all deaths, in order to determine which cases had been referred for medicolegal investigation. This unit is an office of the procurator fiscal, who is equivalent to a coroner in England and Wales. The records describe the circumstances of the death and the previous medical history as recorded by the police after interviews with relatives, witnesses of the death, and the general practitioner of the dead person. Interviews with witnesses of the fatal event are not carried out directly by Glasgow MONICA Project staff. High quality information is collected for the routine reports of the procurator fiscal.

To distinguish the deaths that occurred in hospital from those in people who were dead on arrival (and who were therefore not admitted) hospital case notes and the records of accident and emergency departments were examined for all cases in which a hospital was recorded on the death certificate as the place of death. Similar enquiries were made of appropriate medical and legal departments if death occurred outside Glasgow.

If the details of the circumstances of death and previous medical history could not be obtained from these sources, the information was obtained by sending a reply paid questionnaire to the general practitioner or by reviewing the general practitioner's clinical records after they had been returned to the primary care department of Greater Glasgow Health Board.

The validity of death certificate diagnoses was assessed on the basis of WHO MONICA diagnostic criteria for myocardial infarction and coronary death. ${ }^{6}$ The category of "definite" depends on specified combinations of symptoms, and electrocardiographic, cardiac enzyme, or necropsy findings of cardiac infarction or coronary thrombosis. "Possible" cases are those in which the individual had suggestive symptoms or a previous history of coronary heart disease or necropsy evidence of chronic heart disease and no competing pathology to explain the death. Other categories are "insufficient data" where nothing relevant is known or "no myocardial infarction" when the symptoms and history are inappropriate or there is evidence of another pathology to explain the death.

\section{Results}

\section{ASCERTAINMENT OF DATA}

Information was obtained from at least one source for 419 of the 420 cases.

Two hundred and thirty one police reports were obtained for deaths that occurred outside hospital (including 103 cases that proceeded to a forensic necropsy examination). In one case, which the general practitioner said had been reported to the procurator fiscal, the report could not be found.

Completed questionnaires or records from general practitioners were obtained for 64 of 65 who died outside hospital and whose cases were not referred to the procurator fiscal.

Hospital case notes and electrocardiograms were reviewed for 16 cases: 11 of these received inpatient care in the 28 days before death and subsequently died outside hospital; one patient, who died before arrival at hospital, was admitted direct to a coronary care unit for cardiopulmonary resuscitation lasting two hours; two attended an accident and emergency department during the week before death; one attended an outpatient department 11 days before death, and another was visited at home by a hospital consultant on the day before death.

The records of the accident and emergency department were obtained for only four of the 10 who were dead on arrival at hospital and who were known (from the reports of the procurator fiscal) to have received cardiopulmonary resuscitation.

\section{VALIDITY OF THE DIAGNOSIS}

Three hundred and sixty three cases $(86 \%)$ met the WHO MONICA criteria for "definite" or "possible" myocardial infarction or coronary death, a similar finding to that reported from a comparable study in Belfast. ${ }^{7}$

Seventeen cases $(4 \%)$ were classified "no myocardial infarction" on the basis of clinical or pathological evidence of an alternative cause of death.

Forty cases $(10 \%)$ were categorised as "unknown", because there were insufficient data to ascribe a "definite" or "possible" diagnosis. In only four of these were relevant documents not obtained. For 26 the records were obtained, but information on symptoms before death had not been recorded. In 10 relevant records were obtained and the information recorded was complete, but the information did not meet the criteria for a "definite" or "possible" diagnosis.

These findings indicate that the high coronary mortality in Glasgow is not explained by a high proportion of false positive cases. Because the purpose of the study was to assess the potential impact of preventive strategies on published coronary mortality data, all cases were included in subsequent analyses.

\section{PLACE OF DEATH}

One hundred and twenty three deaths (30\%) occurred in hospital. One hundred and fifteen people died in hospital wards or departments, including two hospital staff at their place of work. Eight people died in accident and emergency departments. The main analyses are based on the 296 deaths $(70 \%)$ that occurred outside hospital. They include 90 cases which were dead on arrival at hospital.

\section{OUT OF HOSPITAL DEATHS}

There were $215(73 \%)$ deaths at home. Fourteen people died at another private address (for example, the home of a relative), 43 in a public place (for example, a social club), 13 died at 
Table 2 Calls for medical help made before death for people with and without symptoms of coronary heart disease

\begin{tabular}{llllc}
\hline & No symptoms (\%) & Symptoms (\%) & Unknown symptoms (\%) & Total (\%) \\
\hline Called before death & 0 & $22(11)$ & $4(10)$ & $26(9)$ \\
Called after death & 52 & $182(89)$ & $36(90)$ & $270(91)$ \\
Total & $52(18)$ & $204(69)$ & $40(13)$ & 296 \\
\hline
\end{tabular}

Table 3 Arrival of general practitioners, ambulance crews, and the police before and after death occurred

\begin{tabular}{|c|c|c|c|c|c|c|c|}
\hline & $G P$ & Ambulance & Police & Hospital & Other & $N K$ & Total \\
\hline $\begin{array}{l}\text { Attended before death } \\
\text { Attended after death } \\
\text { When attended unknown }\end{array}$ & $\begin{array}{r}4 \\
103\end{array}$ & $\begin{array}{r}4 \\
103 \\
8\end{array}$ & 52 & 3 & 4 & 15 & $\begin{array}{r}8 \\
280 \\
8\end{array}$ \\
\hline Total & 107 & 115 & 52 & 3 & 4 & 15 & 296 \\
\hline
\end{tabular}

GP, general practitioner; NK, not known.

work, and five in an ambulance travelling to hospital. Three deaths occurred during transport to hospital in a taxi, a police car, and a private car. For three deaths outside hospital it was not possible to determine the exact place of death.

\section{PREVIOUS ILLNESS}

One hundred and twenty four people (42\%) who died outside hospital had a previous history of coronary heart disease- 72 of them had a previous myocardial infarction and 52 a history of angina.

Forty three $(15 \%)$ had received medical care in the 28 days before death: 13 were hospital inpatients, 22 were seen by their general practitioner or a deputising doctor, three attended an accident and emergency department, three attended an outpatient department, and two were visited at home by a hospital consultant.

\section{CALL FOR MEDICAL HELP}

Only 26 people $(9 \%)$ (table 2 ) called for help before they died and eight were visited by a medical practitioner or by the ambulance service (table 3 ). Three of these deaths occurred at home with the general practitioner in attendance, and five occurred in an ambulance travelling to hospital. In one case the general practitioner was accompanying the patient. Ten deaths occurred before medical help arrived, and in the remaining eight cases it was not possible to determine when death occurred in relation to the arrival of medical help.

\section{SURVIVAL}

The available data do not permit precise estimation of survival times, but at least 140 people $(47 \%)$ are known to have died within an hour of the onset of acute symptoms (table 4). Fifty two deaths were sudden (that is, they were not preceded by reported symptoms), 56 occurred within 10 minutes and another 32 occurred within an hour of the onset of acute symptoms. A further $92(32 \%)$ people were known to have survived less than 24 hours and $24(8 \%)$ survived more than 24 hours. In the remaining $40(14 \%)$ the duration of symptoms before death was not known. There was no difference in the pattern of survival between those with and without a previous medical history of myocardial infarction.

\section{ARRIVAL OF HELP}

Ambulance crews were first to arrive in 115 cases and general practitioners were first to arrive in 107 cases. All but 16 deaths occurred before the call for help was made. Two deaths at work and one at a football stadium were attended first by a medically qualified bystander. Another was first attended by a district nurse, and three other deaths were first confirmed by a hospital casualty doctor. The police were first to arrive in 52 cases. In the remaining 15 cases it was not possible to determine who first attended after death.

\section{CARDIOPULMONARY RESUSCITATION}

One hundred and nineteen deaths $(40 \%)$ were unwitnessed (table 5). The potential for cardiopulmonary resuscitation in these cases depended on how soon after the fatal event the body was discovered. Cardiopulmonary resuscitation was attempted in 10 cases.

In 38 cases $(13 \%)$ it was not recorded whether the death had been witnessed. Of the remaining 139 people whose deaths were witnessed cardiopulmonary resuscitation had been attempted in 48 -in 22 by the person witnessing the death and in 26 by someone who had been called to the scene.

Ambulance crews were first to attempt cardiopulmonary resuscitation in 21 cases. In 20

Table 4 Number (and percentage) of deaths according to survival times from onset of symptoms and previous medical history of myocardial infarction

\begin{tabular}{llllllll}
\hline & 0 min & NKbut $<10$ min & NKbut $<1 h$ & NK but $<24 h$ & NK but $>24 h$ & Not known & Total \\
\hline MI & $14(23)$ & $12(20)$ & $9(15)$ & $20(33)$ & $6(10)$ & 11 & 72 \\
no MI & $38(19)$ & $44(23)$ & $23(12)$ & $72(37)$ & $18(9)$ & 29 & 224 \\
Total & 52 & 56 & 32 & 92 & 24 & 40 & 296 \\
\hline
\end{tabular}

MI, myocardial infarction; NK, not known precisely. 
Table 5 Type of person witnessing the death and attempting cardiopulmonary resuscitation

\begin{tabular}{lcc}
\hline Witness & $\begin{array}{c}\text { Number of } \\
\text { deaths }\end{array}$ & $\begin{array}{l}\text { CPR } \\
\text { attempts }\end{array}$ \\
\hline Spouse & 47 & 4 \\
Other family in household & 25 & 6 \\
Neighbour & 15 & 6 \\
Bystander & 33 & 17 \\
GP/deputy & 4 & 1 \\
Ambulance crew & 4 & 21 \\
Other & 1 & 3 \\
Person unknown & 9 & \\
Nowitness & 119 & \\
Not known whether witnessed & 38 & \\
Total & 296 & 58 \\
\hline
\end{tabular}

CPR, cardiopulmonary resuscitation; GP, general practitioner.

cases cardiopulmonary resuscitation could have been started earlier by the person who either witnessed or was first aware of the death, including two deaths at work. In a further three cases cardiopulmonary resuscitation was initiated by a general practitioner, an off-duty hospital doctor, and a district nurse.

\section{Discussion}

Although coronary mortality in Glasgow is high in international terms, there is no evidence to suggest an unusual pattern of coronary deaths, such as a high incidence of sudden cardiac death. The general pattern of coronary deaths outside hospital is typical and has not changed in 15 years (table 6 ).

Most coronary deaths occurred outside hospital and $85 \%$ of the victims were well in the 28 days before death. These data indicate that the potential for clinical measures to prevent coronary deaths outside hospital lies largely in the circumstances of the fatal event.

In Seattle and neighbouring King County, Washington, over 450000 people have received basic instruction in the techniques of cardiopulmonary resuscitation, and it has been reported that the application of these techniques by lay persons, before the arrival of a mobile coronary care team, can increase long term survival rates from out of hospital cardiac arrest by $50 \%{ }^{8}$

In our study, $40 \%$ of the cardiac arrests outside hospital were unwitnessed. The earliest that cardiopulmonary resuscitation could have been attempted, therefore, was when the death was discovered. When the arrest was witnessed, about one quarter of individuals received cardiopulmonary resuscitation from a lay per-

Table 6 Comparison of fatal cases in Glasgow MONICA 1984 with Tower Hamlets 1970-3

\begin{tabular}{lll}
\hline & $\begin{array}{l}\text { Glasgow MONICA } \\
(n=420)(\%)\end{array}$ & $\begin{array}{l}\text { Tower Hamlets (1 10 11) } \\
(n=350)(\%)\end{array}$ \\
\hline Place of death: & 3 & 7 \\
Work & 51 & 47 \\
Home & 29 & 32 \\
Hospital & 17 & 14 \\
Other & 21 & 34 \\
Dead on arrival at hospital & & 53 \\
Witnessed deaths outside hospital: & 47 & 43 \\
Yes & 40 & 5 \\
No & 13 & \\
Not known & & \\
\hline
\end{tabular}

son before the arrival of medical help. To achieve similar results to those obtained in Seattle, it would be necessary to increase the number of people in the general public who are willing and able to carry out basic techniques in cardiopulmonary resuscitation.

Most deaths from coronary heart disease in Glasgow as in a previous study in Belfast ${ }^{9}$ occurred at home. In deaths that were witnessed by the spouse or another member of the immediate family, cardiopulmonary resuscitation was attempted in only $14 \%$ of cases. Few people died at work, and six out of 13 bystanders in these cases attempted cardiopulmonary resuscitation. Bystanders also initiated cardiopulmonary resuscitation in about a half of witnessed deaths (nine out of 20) that occurred in a public place.

Most $(57 \%)$ of the 87 cases where cardiopulmonary resuscitation could have been attempted, but was not attempted by the person witnessing or discovering the death occurred at home or at another private address in the presence of the spouse or other close relative. Campaigns to educate lay people in the techniques of cardiopulmonary resuscitation, whatever their impact on people in workplace settings or public places, will be of benefit in few cases, unless they lead to resuscitation being attempted by spouses and close relatives at private addresses.

A more selective approach would be to provide instruction in cardiopulmonary resuscitation for the relatives of patients who have survived a myocardial infarction. However, only 15 of the 72 people in the present study with a previous history of myocardial infarction died in the presence of their spouse or another member of the family household. Three of them received cardiopulmonary resuscitation before the arrival of medical help. The maximum impact of a family-based strategy would have been to provide cardiopulmonary resuscitation in 12 cases ( $4 \%$ of all deaths occurring outside hospital).

Because very few deaths (a maximum of 16 but probably nearer eight) occurred in the presence of ambulance crews or general practitioners, the potential benefit that might have been gained just by equipping emergency ambulances and general practitioners with defibrillators would be small in relation to the total number of deaths, however cost-effective these resuscitations may be in themselves.

The data not only show that medical help arrived almost always too late to have any prospect of reversing cardiac arrest, but also that measures to improve response times of general practitioners and ambulance crews are unlikely by themselves to improve the prognosis of people who have an out of hospital cardiac arrest. In $91 \%$ of the cases in this study the fatal collapse had occurred before the call for medical help was made.

For professional interventions to have more chance of success, it would be necessary either for cardiopulmonary resuscitation techniques to be underway when medical help arrives, or for the call for medical help to be made before the fatal collapse occurs. 
It is not possible to tell from these data to what extent the fatal collapse was preceded by a prodromal period during which it may have been possible to make an earlier call for help. However, previous studies in which witnesses of sudden deaths were interviewed found that prodromal symptoms seldom bring patients under medical care more quickly. ${ }^{1011} \mathrm{~A}$ previous study of survivors of myocardial infarction in Glasgow showed a median delay of $4 \cdot 1$ hours in calling for help after the onset of symptoms. ${ }^{12}$ This may not be typical of fatal cases.

We have considered the possibility that these data, which are based on registered deaths, do not take sufficient account of people who survived a cardiac arrest outside hospital, perhaps by provision of cardiopulmonary resuscitation or by prompt defibrillation, and who were then admitted to hospital. Such cases have been registered by the MONICA Project in subsequent years. Six people survived out of hospital cardiac arrest in 1985, and two in 1986 (Morrison C, personal communication). In four cases, cardiac output was reported as having been restored by bystanders, applying cardiopulmonary resuscitation before an ambulance or other medical help arrived. These findings suggest that successful cardiopulmonary resuscitation after a cardiac arrest outside hospital in Glasgow was a rare event in 1984.

There are of course other components of acute medical care for the cardiac arrest such as the relief of pain, treatment of ventricular failure, administration of thrombolytic therapy, and prompt delivery to a coronary care unit. ${ }^{13}$ However, the main contribution of these measures to reducing mortality from coronary heart disease is likely to be an improvement in the prognosis of patients who survive to receive medical attention, most of whom already survive to reach hospital. About one third of all deaths from coronary heart disease belong in this category.

The data are based on events in 1984 when the ambulance service in Glasgow was not equipped to provide resuscitation for cases of cardiac arrest and only responded to direct calls from the general public when somebody had collapsed. They provide a baseline, therefore, against which the effect of developments in care can be assessed. Subsequently, ambulances have been equipped with defibrillators and crews have received training in their use and in cardiopulmonary resuscitation. After reorganisation of the Glasgow ambulance service in 1986, response times to emergency calls have been substantially improved, with $36 \%$ of cases being attended within seven minutes and $92 \%$ witin 14 minutes (Scottish Ambulance Service Statistics, ORCON Standard Times October/ December, 1989). After a report from the National Audit Office in June 1991, the Scottish Office has indicated that additional funding may be made available to the Scottish Ambulance Service to further improve the response time to emergencies in the Glasgow area. We intend to repeat this study to assess the impact of these changes on the outcome of sudden deaths from coronary heart disease in Glasgow.

We are not aware of a previous analysis which assesses the potential impact of community coronary care schemes on the total number of deaths from coronary heart disease outside hospital. In Glasgow in 1984, there were few cases in which the provision of a defibrillator and extended training of ambulance crews could have made a difference to the fatal outcome. The greatest potential for saving lives seems to lie with the relatives of people in middle age.in dealing promptly with acute coronary symptoms, calling for help early, and initiating cardiopulmonary resuscitation, so that these techniques are underway when professional help arrives. Should it prove possible to change behaviour in this area, then the provision of ambulances with defibrillators would have a much greater impact. Without it the number of successes may appear important when summated across the country, or compared with other life-saving services, but they are small both in relation to the total numbers of out of hospital deaths, and the expectations of many who are involved.

We thank the staff of the Glasgow and Dundee MONICA project centres for their help. Scottish MONICA is supported by the Chief Scientist Office, Scottish Home and Health Department The discussion and conclusions of the paper are the responsibility of the authors and do not necessarily reflect the views of the Scottish Home and Health Department.

1 Tunstall-Pedoe $\mathrm{H}$. Uses of coronary heart attack registers. BMJ 1978;40:510-5.

2 Fulton M, Julian DG, Oliver MF. Sudden death and myocardial infarction. Circulation 1969;39 and 40(suppl IV): 182-93

3 Committee of Public Accounts, House of Commons. Coronary heart disease, 26th report. London: HMSO, 1989.

The principal investigators of the MONICA Project. WHO MONICA Project: geographic variation in mortality from cardiovascular disease. World Health Stat $Q$ 1987;40: cardiovascu.

5 WHO MONICA Project Principal Investigators (Prepared by H Tunstall-Pedoe). The World Health Organisation by $H$ Tunstall-Pedoe). The World Health Organisation MONICA Project (Monitoring Trends and Determinants in Cardiovascular Disease): a major inte

6 MONICA MANUAL. 2nd ed. Geneva: Cardiovascular Disease Unit, World Health Organisation, 1990.

7 McIlwaine WJ, Donnelly MDI, Chivers AT, Evans AE Elwood JH. Certification of death from ischaemic hear disease in Belfast. Int J Epidemiol 1985;14:Pb560-5.

8 Cummins RO, Eisenberg MS. Cardiopulmonary resuscita tion-American style. BMJ 1985;291:1401-3.

9 McIlwaine WJ, Donnelly MDI, Mallaghan M, et al. Death from ischaemic heart disease in Belfast. Br Heart $1986 ; 55: 330-5$.

10 Tunstall-Pedoe $H$, Clayton D, Morris JN, Bridgen W, McDonald L. Coronary heart attacks in East London. Lancet 1975;ii:833-8.

11 Tunstall-Pedoe $\mathrm{H}$. A coronary heart attack register in Eas Lond University of Cambridge, 1977, MD. University Microfilms Int 78-70,028.

12 Dunn G, Elms S, Melville DI, Lawrie TDV, Murray TS Farly treatment of myocardial infarction in the commun Early treatment of myoca

13 Mathewson ZM, McCloskey BG, Evans AE, Russell CJ, Wilson $C$. Mobile coronary care and community mortality Wilson C. Mobile coronary care and community 